\title{
Quercetin induces HepG2 cell apoptosis by inhibiting fatty acid biosynthesis
}

\author{
PENG ZHAO $^{1}$, JUN-MIN MAO ${ }^{2}$, SHU-YUN ZHANG $^{3}$, ZE-QUAN ZHOU $^{1}$, YANG TAN $^{1}$ and YU ZHANG ${ }^{1}$ \\ ${ }^{1}$ Health Management Center; Departments of ${ }^{2}$ Traditional Chinese Medicine and ${ }^{3}$ Clinical Laboratory, \\ Hangzhou Sanatorium of PLA, Hangzhou, Zhejiang 310007, P.R. China
}

Received December 6, 2013; Accepted April 30, 2014

DOI: $10.3892 / \mathrm{ol} .2014 .2159$

\begin{abstract}
Quercetin can inhibit the growth of cancer cells with the ability to act as a 'chemopreventer'. Its cancer-preventive effect has been attributed to various mechanisms, including the induction of cell-cycle arrest and/or apoptosis, as well as its antioxidant functions. Quercetin can also reduce adipogenesis. Previous studies have shown that quercetin has potent inhibitory effects on animal fatty acid synthase (FASN). In the present study, activity of quercetin was evaluated in human liver cancer HepG2 cells. Intracellular FASN activity was calculated by measuring the absorption of NADPH via a spectrophotometer. MTT assay was used to test the cell viability, immunoblot analysis was performed to detect FASN expression levels and the apoptotic effect was detected by Hoechst 33258 staining. In the present study, it was found that quercetin could induce apoptosis in human liver cancer HepG2 cells with overexpression of FASN. This apoptosis was accompanied by the reduction of intracellular FASN activity and could be rescued by 25 or $50 \mu \mathrm{M}$ exogenous palmitic acids, the final product of FASN-catalyzed synthesis. These results suggested that the apoptosis induced by quercetin was via the inhibition of FASN. These findings suggested that quercetin may be useful for preventing human liver cancer.
\end{abstract}

\section{Introduction}

Fatty acid synthase (FASN), a metabolic enzyme that catalyzes the synthesis of long-chain fatty acids, is expressed at high levels in adipose tissues and a variety of human cancers, including liver, breast, prostate, endometrium, ovary, colon, lung and pancreatic cancer (1-10). Although the mechanism of FASN overexpression is unknown, it appears to be upregulated during the early stages of tumorigenesis (11). This differential

Correspondence to: Dr Yu Zhang, Health Management Center, Hangzhou Sanatorium of PLA, 5 Longjing Road, Hangzhou, Zhejiang 310007, P.R. China

E-mail: hz128jkgl@163.com

Key words: quercetin, cancer, fatty acid synthase, HepG2 cells, apoptosis expression between normal and neoplastic tissues makes FASN a potential diagnostic tumor marker (12).

Numerous studies suggest that obesity and excess weight play a prominent role in the incidence and progression of various types of cancer (13). Obesity has been associated with a higher risk and a poor prognosis of cancer in multiple studies (14-19). According to a previous study, obesity can increase the mortality of patients with cancer of the liver, breast and kidneys, among others (20). The potential of fatty acid synthesis as a target pathway for chemotherapy has been identified by studies with FASN inhibitors (21).

Studies suggest that dietary polyphenols, such as flavonoids, exert high inhibitory effects on FASN (22-28). Quercetin (3,3',4',5,7-pentahydroxyflavone) (Fig. 1A), an important dietary flavonoid present in red onions, apples, berries, citrus fruits, tea and red wine (29), exhibits antioxidant, anti-inflammatory, anti-obesity and anticancer properties (30). Quercetin has received increasing attention as a pro-apoptotic flavonoid with specific, and almost exclusive, effects on tumor cells rather than normal, non-transformed cells $(31,32)$.

Quercetin has been reported to provide an improved health status to its consumers, particularly with regard to obesity and diabetes (33). Studies have demonstrated that quercetin can modestly reduce weight and regulate the expression of genes related to in vitro adipogenesis $(34,35)$. However, the mechanisms by which quercetin exerts these anticancer and anti-obesity effects remains unclear.

Therefore, the present study aimed to examine whether the anticancer activity of quercetin is associated with its anti-obesity effects. This study investigated the inhibitory effect of quercetin on human liver HepG2 cancer cells with overexpression of FASN.

\section{Materials and methods}

Reagents and antibodies. Quercetin, acetyl-CoA, alonyl-CoA, dexamethasone, Hoechst 33258, insulin, NADPH, MTT dye, 3-isobutyl-1-methylxanthine, palmitic acid, EDTA and DTT were purchased from Sigma-Aldrich (St. Louis, MO, USA). Dulbecco's modified Eagle's medium (DMEM) and fetal bovine serum were purchased from Gibco-BRL (Gaithersburg, MD, USA) and the penicillin-streptomycin was purchased from Oriental Bio-Technology Co., Ltd. (Beijing, China). Rabbit anti-human polyclonal FASN and 
mouse anti-human monoclonal GAPDH antibodies were purchased from Cell Signaling Technology, Inc. (Beverly, MA, USA).

Cell culture. Human liver cancer HepG2 cells were obtained from the Cell Bank of the Chinese Academy of Sciences (Shanghai, China). Cells were incubated in DMEM (high-glucose), $10 \%$ fetal bovine serum and $100 \mathrm{U} / \mathrm{ml}$ penicillin-streptomycin.

MTT assay. HepG2 cells were seeded in a 96-well plate $\left(5 \times 10^{3}\right.$ cells/well) and then treated with quercetin at different concentrations for $24 \mathrm{~h}$. Thereafter, $20 \mathrm{ml}$ of MTT solution [5 mg MTT/ml in phosphate-buffered saline (PBS)] was added into each well of a microtiter plate and incubated for $4 \mathrm{~h}$ at $37^{\circ} \mathrm{C}$. The resultant formazan product was dissolved in $200 \mathrm{ml}$ dimethylsulfoxide/well, and its concentration was measured at $492 \mathrm{~nm}$ by a microplate reader (Model EL 307C; BioTek, Shanghai, China).

Cell lysis and immunoblotting. Cells were lysed as previously described (36) and the cell lysates were heated in a water bath to fully denature the proteins. The proteins were then separated by SDS-PAGE [Bio-Rad Laboratories (Shanghai) Ltd., Shanghai, China] and transferred to polyvinylidene difluoride membranes (Immobilon; Millipore, Billerica, MA, USA). Immunoblotting was performed with antibodies against FASN and GAPDH, and visualized using an enhanced chemiluminescence light detection kit (Amersham, Piscataway, NJ, USA).

Cell apoptosis assay. HepG2 cells were seeded in 12-well culture dishes $\left(5 \times 10^{4}\right.$ cells/well). Following experimental treatment with 25 and $50 \mu \mathrm{M}$ quercetin for $24 \mathrm{~h}$, cells were washed twice with PBS, stained with Hoechst 33258 $(5 \mathrm{mg} / \mathrm{ml})$ for $5 \mathrm{~min}$ in the dark, and then washed extensively three times with PBS. Nuclear staining was examined under a fluorescence microscope (Nikon LH-M100CB; Jirui Co., Ltd., Suzhou, China) and images were captured using Image-Pro Plus software (MediaCybernetics, Silver Spring, MD, USA).

Intracellular fatty acids assay. The amount of intracellular fatty acid was determined by the Fatty Acid Assay kit (Lab-Bio Co., Ltd., Beijing, China). Briefly, HepG2 cells were seeded in $100-\mathrm{mm}$ cell culture dishes. Following experimental treatment, cells were washed twice with PBS and then extracted by homogenization with $200 \mu \mathrm{l}$ chloroform-Triton X-100 (1\% Triton X-100 in pure chloroform; Shanghai XiTang Biotechnology Co., Ltd., Shanghai, China) in a microhomogenizer. Subsequently, the extract was centrifuged for 5-10 min at high speed $(16,000 \mathrm{x} \mathrm{g})$. The organic (lower) phase was collected and air-dried at $50^{\circ} \mathrm{C}$ to remove the chloroform, followed by vacuum-drying for $30 \mathrm{~min}$ to remove trace chloroform. The dried lipids were dissolved in $200 \mu 1$ Fatty Acid Assay buffer by vortexing extensively for $5 \mathrm{~min}$. Next, $2 \mu \mathrm{l}$ acyl-CoA synthetase reagent was added to all sample wells and the samples were incubated at $37^{\circ} \mathrm{C}$ for $30 \mathrm{~min}$. Following this, $50 \mu 1$ reaction mix containing $44 \mu 1$ Fatty Acid Assay buffer, $2 \mu 1$ Fatty Acid Assay probe,<smiles>O=c1c(O)c(-c2ccc(O)c(O)c2)oc2cc(O)cc(O)c12</smiles>

B

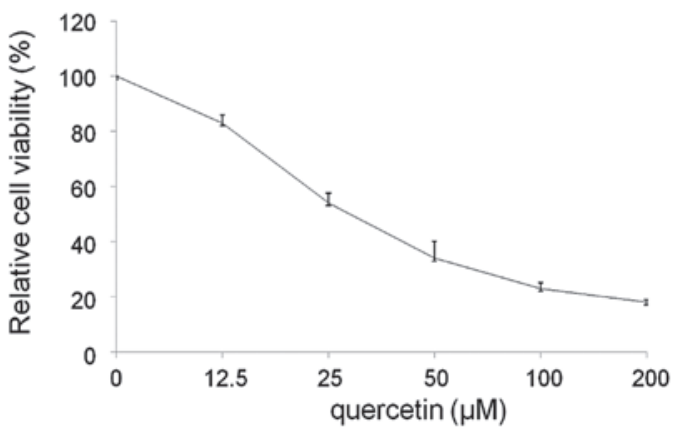

Figure 1. Dose-dependent inhibitory effects of quercetin on the viability of HepG2 cells. (A) Chemical structure of quercetin. (B) Cell viability was determined by MTT assay. HepG2 cells were incubated with quercetin for $24 \mathrm{~h}$ at the concentrations of $0-200 \mu \mathrm{M}$. $\mathrm{IC}_{50}=24 \mu \mathrm{M}$. Bars represent the mean $\pm \mathrm{SD}$.

A

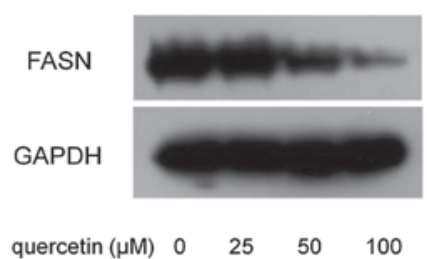

B

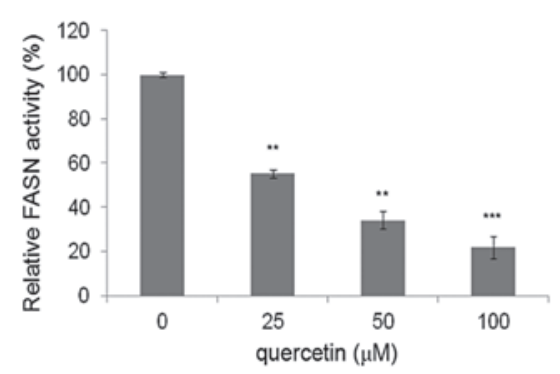

C

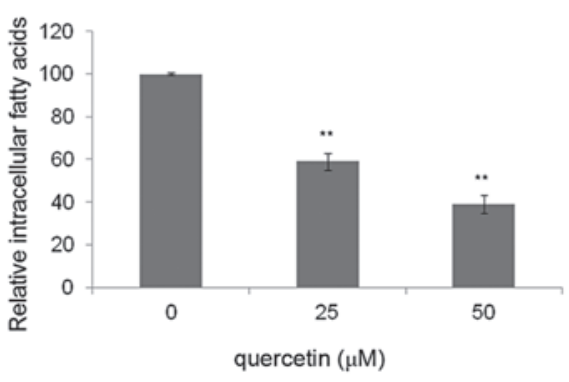

Figure 2. Effects of quercetin on FASN expression and activity. (A) Effect of quercetin on FASN expression. Cells were treated with $0,25,50$ and $100 \mu \mathrm{M}$ quercetin. After $24 \mathrm{~h}$, cells were harvested and analyzed by western blotting. (B) FASN activity assay was performed as described in Materials and methods. Data were normalized to those of control cells without quercetin $(0 \mu \mathrm{M})$. Relative FASN activity is presented as the mean $\pm \mathrm{SD}$. ${ }^{*} \mathrm{P}<0.05$, ${ }^{* * *} \mathrm{P}<0.01$ and ${ }^{* * *} \mathrm{P}<0.001$, compared with the control, respectively. (C) HepG2 cells were treated with quercetin at various concentrations $(0,25$ and $50 \mu \mathrm{M})$ for $24 \mathrm{~h}$. The amount of intracellular fatty acid was then determined by the Fatty Acid Assay kit. Data were expressed as the mean $\pm \mathrm{SD}$. $(\mathrm{n}=3)$. ${ }^{* *} \mathrm{P}<0.01$, compared with the respective control. FASN, fatty acid synthase 


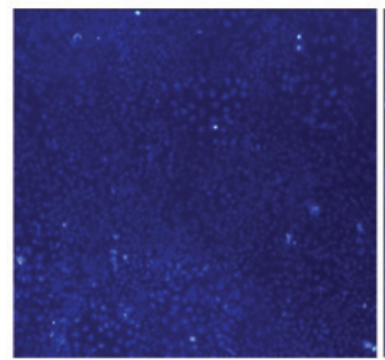

0

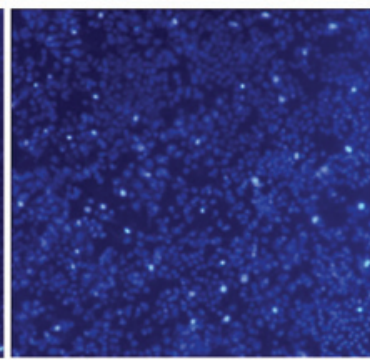

25

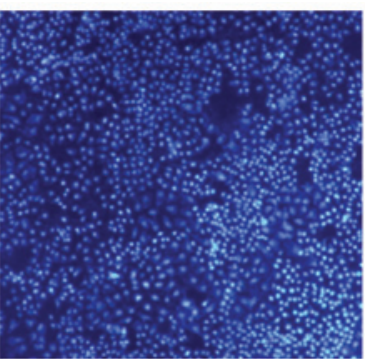

50

\section{quercetin $(\mu \mathrm{M})$}

Figure 3. Apoptotic effect of quercetin on HepG2 cells. Cell culture was performed as described in Materials and methods. Photographs of HepG2 cells were taken after Hoechst 33258 staining. The concentrations of quercetin were 0,25 and $50 \mu \mathrm{M}$.

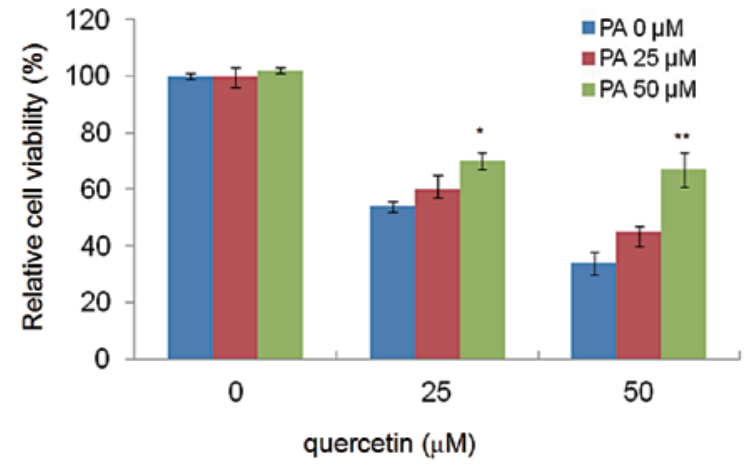

Figure 4. Sodium palmitate rescued HepG2 cell apoptosis induced by quercetin. Sodium palmitate $(0,25$ and $50 \mu \mathrm{M})$ was added to cells in the presence of 0,25 and $50 \mu \mathrm{M}$ quercetin. After $24 \mathrm{~h}$, MTT assay was used to analyze the cell viability. Bars represent the mean \pm SD.

$2 \mu 1$ enzyme mix and $2 \mu 1$ enhancer, was added to the test samples. The samples were then incubated for $30 \mathrm{~min}$ at $37^{\circ} \mathrm{C}$, whilst being protected from light. The colorimetric assay was conducted by measuring the absorbance at $570 \mathrm{~nm}$ using a microplate reader.

Cell FASN activity assay. FASN activity in cells was assessed as described previously (37). Briefly, cells were harvested, pelleted by centrifugation at $18,000 \mathrm{x} \mathrm{g}$ for $30 \mathrm{~min}$, resuspended in cold assay buffer $(100 \mathrm{mM}$ potassium phosphate buffer, $1 \mathrm{mM}$ EDTA, 0.6 mM PMSF and $1 \mathrm{mM}$ dithiolthreitol, $\mathrm{pH}$ 7.0) ultrasonically disrupted and centrifuged at $16,000 \mathrm{x}$ g for $30 \mathrm{~min}$ at $4^{\circ} \mathrm{C}$. The supernatant was then collected for the overall reaction assay. A total of $25 \mathrm{ml}$ supernatant was added to the reaction mix containing $25 \mathrm{mM} \mathrm{KH}_{2} \mathrm{PO}_{4}-\mathrm{K}_{2} \mathrm{HPO}_{4}$ buffer, $0.25 \mathrm{mM}$ EDTA, $0.25 \mathrm{mM}$ dithiothreitol, $30 \mathrm{mM}$ acetyl-CoA, $100 \mathrm{mM}$ malonyl-CoA and $350 \mathrm{mM}$ NADPH (pH 7.0), in a total volume of $200 \mathrm{ml}$. Protein content in the supernatant was determined using a bicinchoninic acid assay (Pierce, Rockford, IL, USA) and results were expressed as the specific activity of FASN at the same protein concentration as the control group $(0 \mu \mathrm{M}$ quercetin).

Palmitic acid assay. HepG2 cells were exposed for $24 \mathrm{~h}$ to various concentrations of quercetin $(0,25$ and $50 \mu \mathrm{M})$ in the presence of exogenous palmitic acid $(0,25$ and $50 \mu \mathrm{M})$, the end product of the FASN reaction. Next, the relative cell viabilities were analyzed by MTT assay.

Statistical analysis. The results were analyzed by one way analysis of variance (origin 8.0 ). $\mathrm{P}<0.05$ was considered to indicate a statistically significant difference, while $\mathrm{P}<0.01$ was considered to indicate a markedly significant difference.

\section{Results}

Inhibitory effects of quercetin on viability of HepG2 cells in vitro. To identify whether quercetin influences the survival of HepG2 cells, cells were treated with 0-200 $\mu \mathrm{M}$ quercetin and cell viability was examined by MTT assay. As shown in Fig. 1B, HepG2 cell viability was reduced to $52 \%$ with $25 \mu \mathrm{M}$ quercetin and to $34 \%$ with $50 \mu \mathrm{M}$ quercetin. Cell growth was markedly suppressed by $82 \%$ following treatment with $200 \mu \mathrm{M}$ quercetin, when compared with the control $(0 \mu \mathrm{M})$. Quercetin showed high inhibition of cell population growth in a dose-dependent manner with a $50 \%$ growth inhibitory concentration $\left(\mathrm{IC}_{50}\right)$ value of $24 \mu \mathrm{M}$.

Quercetin inhibits FASN expression and activity in HepG2 cells. The effect of quercetin on the expression of FASN in HepG2 cells. was investigated. As shown in Fig. 2A, compared with the control, the cells treated with quercetin showed markedly lower levels of FASN. This suggests that the FASN expression levels were significantly suppressed by quercetin. Compared with the control, quercetin significantly inhibited the intracellular FAS activity in a dose-dependent manner. As shown in Fig. 2B, HepG2 cells were treated with quercetin at a concentration of 25, 50 and $100 \mu \mathrm{M}$ for $24 \mathrm{~h}$. Intracellular FASN activity was reduced to 55.6, 34.3 and $22.1 \%$, respectively, compared with control.

Quercetin reduces intracellular fatty acids in HepG2 cells. The levels of intracellular fatty acids in HepG2 cells treated with 25 and $50 \mu \mathrm{M}$ quercetin were measured, as these concentrations were able to reduce cell viability with $\mathrm{IC}_{50}$ values of 25 and $50 \mu \mathrm{M}$ and downregulate FASN expression significantly. The results showed that the levels of intracellular fatty acids in treated cells decreased by 40.6 and $60.8 \%$, compared with the control (0 $\mu \mathrm{M}$ quercetin) (Fig. 2C). 
Quercetin induces Hep 62 cells apoptosis. In order to examine whether the inhibitory effect of quercetin on HepG2 cells was due to apoptotic cell death, apoptotic events of Hoechst 33258 staining were investigated. Following exposure to three different concentrations of quercetin $(0,25$ and $50 \mu \mathrm{M})$ for $24 \mathrm{~h}$, apoptosis of HepG2 cells was demonstrated by Hoechst 33258 staining, revealing cell membrane permeability increases and nuclear condensation in a dose-dependent manner (Fig. 3).

Palmitic acid rescues cell apoptosis induced by quercetin. To confirm that the cell apoptosis induced by quercetin was related to FASN inhibition, HepG2 cells were exposed to different concentrations of quercetin $(0,25$ and $50 \mu \mathrm{M})$ for $24 \mathrm{~h}$, in the presence of exogenous palmitic acid $(0,25$ and $50 \mu \mathrm{M})$, the end product of the FASN reaction. Palmitic acid reduced the cytotoxic effects of quercetin, and the cell viabilities were restored significantly and in a dose-dependent manner (Fig. 4).

\section{Discussion}

Dietary phytochemicals consist of a wide variety of biologically active compounds that are ubiquitous in plants, a number of which have been reported to have antitumor properties. Among these, quercetin, which is abundant in red onions, apples, berries, citrus fruits, tea and red wine, has been reported to have therapeutic potential for treating numerous types of human cancer (38-43). Quercetin is well-known for its benefits for weight control and cancer prevention. However, to date, no association has been reported between its anti-obesity and cancer prevention activities.

Inhibition of FASN in cancer cells has been found to induce apoptosis, which suggests that inhibiting intracellular FASN should be a reasonable way for the treatment of cancer $(44,45)$. $\mathrm{Li}$ and Tian have reported that quercetin is a natural and potent FASN inhibitor with an $\mathrm{IC}_{50}$ value of $4.29 \pm 0.34 \mu \mathrm{M}(46)$. The present study showed that quercetin induced liver cancer cell apoptosis via inhibition of FASN.

FASN is a key enzyme participating in lipogenesis and the de novo synthesis of palmitate from Ac-CoA, Mal-CoA and NADPH, and plays an important role in converting excess carbon intake into fatty acids for energy storage $(2,47)$. In normal tissue, FASN levels are generally low, as the requirement of quiescent cells for fatty acids is generally provided via dietary fatty acids. However, in rapidly proliferating cancer cells, such as liver, prostate, ovarian, breast, endometrial and thyroid carcinomas, FASN is overexpressed (2). Overexpression of FASN in cancer cells suggests that tumors require higher levels of fatty acids than can be acquired from the circulation, but also indicates higher levels of endogenous production. Elevated expression of FASN has been linked to poor prognosis and reduced disease-free survival in numerous types of cancer (48). RNAi knockdown experiments have shown that multiple cancer cell lines depend on FASN for proliferation and survival. FASN appears to play a key role in tumor initiation and propagation for a number of malignancies, and represents an attractive target for cancer treatment. Although the ultimate mechanism of cancer-associated FASN overexpression is not completely understood, it has been shown that FASN inhibitors such as C75 and orlistat are promising potential anticancer drugs. It is necessary to discover additional FASN inhibitors that may be applied practically in the treatment of cancer.

High expression of FASN in human liver, breast, colorectal, prostate, endometrial, ovary and thyroid cancer supports the hypothesis that FASN is essential for generating cell membranes during tumor cell proliferation (49). In the present study, it was found that quercetin not only exerted a high inhibitory effect on intracellular FASN, but also influenced the normal life cycle of cancer cells (Fig. 1B and C). These results suggested that FASN, a target for treating cancer, was also a target of quercetin.

The activity of FASN in cells affects the levels of intracellular fatty acids, as FASN plays a key role in de novo fatty acid biosynthesis. Considering that quercetin has been found in numerous edible plants, it may be safe to assume that a high intake of quercetin is safe.

In the current study, similar to reported FASN inhibitors, such as C75 and cerulenin (21), quercetin could induce apoptosis in cancer cells (Fig. 2C). Previous studies have suggested that the mechanism of apoptosis through inhibiting FASN could be explained by the accumulation of malonyl-CoA, which was likely to trigger cancer cell death and induce apoptosis $(50,51)$. It was proposed that certain signaling pathways involved in cell apoptosis were closely associated with the inhibition of FASN, which may help to explain why FASN inhibitors may potentially be used to treat cancer.

Certain studies, however, have shown that palmitic acid, the final product of FASN, is important for the formation of cell membranes (52). Therefore, the reduction of synthesized palmitic acid may be another reason to explain why the inhibition of FASN could induce apoptosis. In the current study, it was found that the reduced cell viabilities induced by quercetin treatment could be rescued by adding exogenous palmitic acid, which provided strong evidence for the cell membrane thesis (Fig. 2D and Fig. 3C).

In conclusion, the present study demonstrated that quercetin could induce HepG2 cells apoptosis via inhibition of intracellular FASN activity and downregulation of FASN expression. The finding that palmitic acid rescued quercetin-induced apoptosis in cancer cells confirmed that the induction of apoptosis was associated with the inhibition of FASN. As quercetin showed potent inhibitory effects on the proliferation of HepG2 cells, it has the potential to be developed into a candidate drug for treating human liver cancer.

\section{References}

1. Alo' PL, Visca P, Marci A, Mangoni A, Botti C and Di Tondo U: Expression of fatty acid synthase (FAS) as a predictor of recurrence in stage I breast carcinoma patients. Cancer 77: 474-482, 1996.

2. Milgraum LZ, Witters LA, Pasternack GR and Kuhajda FP: Enzymes of the fatty acid synthesis pathway are highly expressed in in situ breast carcinoma. Clin Cancer Res 3: 2115-2120, 1997

3. Epstein JI, Carmichael M and Partin AW: OA-519 (fatty acid synthase) as an independent predictor of pathologic state in adenocarcinoma of the prostate. Urology 45: 81-86, 1995.

4. Swinnen JV, Roskams T, Joniau S, Van Poppel H, Oyen R, Baert L, Heyns W and Verhoeven G: Overexpression of fatty acid synthase is an early and common event in the development of prostate cancer. Int J Cancer 98: 19-22, 2002.

5. Pizer ES, Lax SF, Kuhajda FP, Pasternack GR and Kurman RJ: Fatty acid synthase expression in endometrial carcinoma: correlation with cell proliferation and hormone receptors. Cancer 83: 528-537, 1998. 
6. Gansler TS, Hardman W III, Hunt DA, Schaffel S and Hennigar RA: Increased expression of fatty acid synthase (OA-519) in ovarian neoplasms predicts shorter survival. Hum Pathol 28: 686-692, 1997.

7. Rashid A, Pizer ES, Moga M, Milgraum LZ, Zahurak M, Pasternack GR, Kuhajda FP and Hamilton SR: Elevated expression of fatty acid synthase and fatty acid synthetic activity in colorectal neoplasia. Am J Pathol 150: 201-208, 1997.

8. Orita H, Coulter J, Tully E, Kuhajda FP and Gabrielson E: Inhibiting fatty acid synthase for chemoprevention of chemically induced lung tumors. Clin Cancer Res 14: 2458-2464, 2008.

9. Visca P, Sebastiani V, Botti C, Diodoro MG, Lasagni RP, Romagnoli F, Brenna A, De Joannon BC, Donnorso RP, Lombardi G and Alo PL: Fatty acid synthase (FAS) is a marker of increased risk of recurrence in lung carcinoma. Anticancer Res 2: 4169-4173, 2004.

10. Alo PL, Amini M, Piro F, et al: Immunohistochemical expression and prognostic significance of fatty acid synthase in pancreatic carcinoma. Anticancer Res 27: 2523-2527, 2007.

11. Kuhajda FP: Fatty-acid synthase and human cancer: new perspectives on its role in tumor biology. Nutrition 16: 202-208, 2000.

12. Walter K, Hong SM, Nyhan S, et al: Serum fatty acid synthase as a marker of pancreatic neoplasia. Cancer Epidem Biomar 18: 2380-2385, 2009.

13. Prieto-Hontoria PL, Pérez-Matute P, Fernández-Galilea M, et al: Role of obesity-associated dysfunctional adipose tissue in cancer: a molecular nutrition approach. Biochim Biophys Acta 1807: 664-678, 2011.

14. Tartter PI, Papatestas AE, Ioannovich J, Mulvihill MN, Lesnick G and Aufses AH Jr: Cholesterol and obesity as prognostic factors in breast cancer. Cancer 47: 2222-2227, 1981 .

15. van den Brandt PA, Spiegelman D, Yaun SS, et al: Pooled analysis of prospective cohort studies on height, weight, and breast cancer risk. Am J Epidemiol 152: 514-527, 2000.

16. Lahmann PH, Hoffmann K, Allen N, et al: Body size and breast cancer risk: findings from the European Prospective Investigation into Cancer and Nutrition (EPIC). Int J Cancer 111: 762-771, 2004

17. Kroenke CH, Chen WY, Rosner B and Holmes MD: Weight, weight gain, and survival after breast cancer diagnosis. J Clin Oncol 23: 1370-1378, 2005.

18. Caan BJ, Kwan ML, Hartzell G, et al: Pre-diagnosis body mass index, post-diagnosis weight change, and prognosis among women with early stage breast cancer. Cancer Cause Control 19: 1319-1328, 2008.

19. Dawood S, Broglio K, Gonzalez-Angulo AM, Kau SW, Islam R, Hortobagyi GN and Cristofanilli M: Prognostic value of body mass index in locally advanced breast cancer. Clin Cancer Res 14: 1718-1725, 2008.

20. Calle EE, Rodriguez C, Walker-Thurmond $\mathrm{K}$ and Thun MJ: Overweight, obesity, and mortality from cancer in a prospectively studied cohort of U.S. adults. New Engl J Med 348: 1625-1638, 2003

21. Kuhajda FP: Fatty acid synthase and cancer: new application of an old pathway. Cancer Res 66: 5977-5980, 2006.

22. Fan $\mathrm{H}, \mathrm{Wu} \mathrm{D}$, Tian $\mathrm{W}$ and $\mathrm{Ma} \mathrm{X}$ : Inhibitory effects of tannic acid on fatty acid synthase and 3T3-L1 preadipocyte. Biochim Biophys Acta 1831: 1260-1266, 2013.

23. Wu D, Ma X and Tian W: Pomegranate husk extract, punicalagin and ellagic acid inhibit fatty acid synthase and adipogenesis of 3T3-L1 adipocyte. J Funct Food 5: 633-641, 2013.

24. Wang Y, Tian $W$ and Ma X: Inhibitory effects of onion (Allium cepa L.) extract on proliferation of cancer cells and adipocytes via inhibiting fatty acid synthase. Asian Pacific J Cancer Prev 13: 5573-5579, 2012.

25. Quan X, Wang Y, Ma X, et al: $\alpha$-Mangostin induces apoptosis and suppresses differentiation of 3T3-L1 cells via inhibiting fatty acid synthase. PLoS One 7: e33376, 2012.

26. Jiang HZ, Ma QY, Fan HJ, et al: Fatty acid synthase inhibitors isolated from Punica granatum L. J Braz Chem Soc 23: 889-893, 2012.

27. Jiang HZ, Quan XF, Tian WX, et al: Fatty acid synthase inhibitors of phenolic constituents isolated from Garcinia mangostana. Bioorg Med Chem Lett 20: 6045-6047, 2010.

28. Fan H, Tian W and Ma X: Curcumin induces apoptosis of HepG2 cells via inhibiting fatty acid synthase. Targ Oncol: Jul 3, 3013 (Epub ahead of print). doi: 10.1007/s11523-013-0286-5.

29. Erlund I: Review of the flavonoids quercetin, hesperetin, and naringenin. Dietary sources, bioactivities, bioavailability, and epidemiology. Nutr Res 24: 851-874, 2004.
30. Gibellini L, Pinti M, Nasi M, et al: Quercetin and cancer chemoprevention. Evid Based Complement Alternat Med 2011: 591356, 2011

31. Park MH and Min do S: Quercetin-induced downregulation of phospholipase D1 inhibits proliferation and invasion in U87 glioma cells. Biochem Biophys Res Commun 412: 710-715, 2011

32. Du G, Lin H, Wang M, et al: Quercetin greatly improved therapeutic index of doxorubicin against 4T1 breast cancer by its opposing effects on HIF-1 $\alpha$ in tumor and normal cells. Cancer Chemother Pharmacol 65: 277-287, 2010.

33. Leiherer A, Mündlein A and Drexel H: Phytochemicals and their impact on adipose tissue inflammation and diabetes. Vascul Pharmacol 58: 3-20, 2013.

34. Hurt RT and Wilson T: Geriatric obesity: evaluating the evidence for the use of flavonoids to promote weight loss. J Nutr Gerontol Geriatr 31: 269-289, 2012

35. Arcari DP, Santos JC, Gambero A and Ribeiro ML: The in vitro and in vivo effects of yerba mate (Ilex paraguariensis) extract on adipogenesis. Food Chem 141: 809-815, 2013.

36. Uddin S, Ah-Kang J, Ulaszek J, Mahmud D and Wickrema A: Differentiation stage-specific activation of p38 mitogen-activated protein kinase isoforms in primary human erythroid cells. Proc Natl Acad Sci USA 101: 147-152, 2004.

37. Menendez JA, Mehmi I, Atlas E, Colomer R and Lupu R: Novel signaling molecules implicated in tumor-associated fatty acid synthase-dependent breast cancer cell proliferation and survival: Role of exogenous dietary fatty acids, p53-p21WAF1/CIP1, ERK1/2 MAPK, p27KIP1, BRCA1, and NF-kappaB. Int J Oncol 24: 591-608, 2004

38. Angst E, Park JL, Moro A, et al: The flavonoid quercetin inhibits pancreatic cancer growth in vitro and in vivo. Pancreas 42 : 223-229, 2013.

39. Del Follo-Martinez A, Banerjee N, Li X, Safe S and Mertens-Talcott $S$ : Resveratrol and quercetin in combination have anticancer activity in colon cancer cells and repress oncogenic microRNA-27a. Nutr Cancer 65: 494-504, 2013.

40. Berndt K, Campanile C, Muff R, Strehler E, Born W and Fuchs B: Evaluation of quercetin as a potential drug in osteosarcoma treatment. Anticancer Res 33: 1297-1306, 2013.

41. Gao X, Wang B, Wei X, et al: Anticancer effect and mechanism of polymer micelle-encapsulated quercetin on ovarian cancer. Nanoscale 4: 7021-7030, 2012.

42. Lai WW, Hsu SC, Chueh FS, et al: Quercetin inhibits migration and invasion of SAS human oral cancer cells through inhibition of NF- $\kappa \mathrm{B}$ and matrix metalloproteinase-2/-9 signaling pathways. Anticancer Res 33: 1941-1950, 2013.

43. Lam TK, Shao S, Zhao Y, et al: Influence of quercetin-rich food intake on microRNA expression in lung cancer tissues. Cancer Epidemiol Biomarkers Prev 21: 2176-2184, 2012.

44. Zhang SY, Ma XF, Zheng CG, Wang Y, Cao XL and Tian WX: Novel and potent inhibitors of fatty acid synthase derived from catechins and their inhibition on MCF-7 cells. J Enzyme Inhib Med Chem 24: 623-631, 2009.

45. Li P, Tian W, Wang X and Ma X: Inhibitory effect of desoxyrhaponticin and rhaponticin, two natural stilbene glycosides from the Tibetan medicinal plant Rheum tanguticum Maxim. ex Balf., on fatty acid synthase and human breast cancer cells. Food Funct 5: 251-256, 2014.

46. Li BH and Tian WX: Inhibitory effects of flavonoids on animal fatty acid synthase. J Biochem 135: 85-91, 2004.

47. Aggarwal BB and Shishodia S: Molecular targets of dietary agents for prevention and therapy of cancer. Biochem Pharmacol 71: 1397-1421, 2006.

48. Bandyopadhyay S, Pai SK, Watabe M, et al: FAS expression inversely correlates with PTEN level in prostate cancer and a PI3-kinase inhibitor synergizes with FAS siRNA to induce apoptosis. Oncogene 24: 5389-5395, 2005.

49. Menendez JA and Lupu R: Fatty acid synthase and the lipogenic phenotype in cancer pathogenesis. Nature Rev Cancer 7: 763-777, 2007.

50. Pizer ES, Thupari J, Han WF, et al: Malonyl-coenzymeA is a potential mediator of cytotoxicity induced by fatty-acid synthase inhibition in human breast cancer cells and xenografts. Cancer Res 60: 213-218, 2000

51. Zhou W, Simpson PJ, McFadden JM, et al: Fatty acid synthase inhibition triggers apoptosis during $\mathrm{S}$ phase in human cancer cells. Cancer Res 63: 7330-7337, 2003.

52. Murthy S, Albright E, Mathur SN and Field FJ: Modification of CaCo-2 cell membrane fatty acid composition by eicosapentaenoic acid and palmitic acid: effect on cholesterol metabolism. J Lipid Res 29: 773-780. 1988 